\title{
Arrendamento de terras e agricultura familiar na região meio oeste de Santa Catarina
}

\author{
Leasing of land and family farming in the Midwest region of Santa Catarina \\ Arrendamiento de tierras y agricultura familiar en la región oeste del estado de \\ Santa Catarina
}

\author{
Ana Cecília Guedes ${ }^{1}$ \\ Ademir Antonio Cazella ${ }^{1}$
}

Recebido em 08/03/2018; revisado e aprovado em 15/08/2018; aceito em 23/08/2018

DOI: http://dx.doi.org/10.20435/inter.v20i4.1877

\begin{abstract}
Resumo: Este artigo analisa o arrendamento de terras, com ênfase nas diferentes relações entre agricultores familiares. Teoricamente articula as noções de ciclo de vida familiar de Chayanov (1899/1974) e de mobilidades substanciais de Shanin (1983). A metodologia consistiu em entrevistas com agricultores e proprietários de terras do oeste catarinense. O arrendamento de terras amplia os negócios agropecuários de parcela de agricultores familiares e está associado à aposentadoria rural de outra parcela.

Palavras-chave: contratos agrários; acesso a terra; ciclo de vida; desenvolvimento rural.

Abstract: This paper analyzes land leasing, with an emphasis on the different relationships between family farmers. It theoretically articulates the notions of Chayanov's family life cycle (1899/1974) and the substantial mobility of Shanin (1983). The methodology consisted in interviews with farmers and landowners from the West of Santa Catarina. The lease of land expands the agricultural business for a portion of family farmers and is associated with the rural retirement of another part.

Keywords: agricultural contracts; access to land; life cycle; rural development.

Resumen: Este artículo presenta el análisis del arrendamiento de tierras en el oeste catarinense, con énfasis en las diferentes relaciones entre agricultores familiares. Teóricamente articula las nociones del ciclo de vida familiar de Chayanov (1899/1974) y de las movilidades sustanciales de Shanin (1983). La metodología consistió en entrevistas con agricultores arrendatarios y propietarios de tierras. El arrendamiento de tierras permite ampliar los negocios agropecuarios de agricultores familiares, y en otros casos está asociado a la jubilación rural.
\end{abstract}

Palabras clave: contratos agrícolas; acceso a tierra; ciclo de vida; desarrollo rural.

\section{INTRODUÇÃO}

Os contratos agrários de arrendamento, embora sejam recorrentes em todo o território nacional e uma prática relativamente antiga, de forma geral, são pouco conhecidos e analisados. Os estudos sobre a temática quase sempre estiveram associados a uma conotação negativa, ao enfatizarem as relações de precariedade, submissão aos grandes proprietários de terras e pobreza dos agricultores arrendatários. Embora esse tipo de relação ainda persista no meio rural, uma parcela da agricultura familiar brasileira está recorrendo a esse mecanismo de acesso a terras para ampliar e viabilizar os seus negócios agropecuários. Segundo o Estatuto da Terra de 1964 (BRASIL, 1985), o arrendatário consiste na pessoa ou conjunto familiar, representado pelo seu chefe, que recebe ou toma por aluguel os bens de terceiros. O arrendador de terras, por sua vez, é aquele que disponibiliza os seus bens para o arrendamento de terceiros.

O objetivo deste artigo foi analisar o arrendamento de terras como uma estratégia de reprodução social associada ao ciclo de vida familiar de parcelas de agricultores, tanto de quem arrenda terras de terceiros quanto de quem cede as suas terras para terceiros. A abordagem teórica está

\footnotetext{
${ }^{1}$ Universidade Federal de Santa Catarina (UFSC), Florianópolis, Santa Catarina, Brasil.
} 
ancorada na teoria do ciclo de vida familiar, também denominada de diferenciação demográfica, elaborada por Chayanov (1899/1974), segundo a qual o tamanho da família aumenta e diminui ao longo do ciclo de existência de uma unidade agrícola familiar, adaptando as suas estratégias de sobrevivência e de uso da terra às suas necessidades de consumo. A teoria de Shanin (1972/1983) complementa a teoria de Chayanov, afirmando que as determinantes demográficas induzem a distintas diferenças econômicas e mobilidades das unidades agrícolas familiares.

O público-alvo deste estudo compõe-se de agricultores e de proprietários de terras absenteístas $^{2}$ envolvidos nos contratos de arrendamento de terras. A escolha de arrendadores e arrendatários deu-se com o auxílio de informantes-chave dos municípios, com destaque para extensionistas rurais da Empresa de Pesquisa Agropecuária e Extensão Rural de Santa Catarina, dirigentes de Sindicatos dos Trabalhadores Rurais e gestores de secretarias municipais da Agricultura.

Os dados foram coletados em seis municípios da região meio oeste de Santa Catarina: Bom Jesus, Entre Rios, Faxinal dos Guedes, Ipuaçu, Vargeão e Xanxerê. A coleta de dados a campo ocorreu por meio de entrevistas semiestruturadas com questões abertas e fechadas, conduzidas com o auxílio de diário de campo, gravação de áudio e registro escrito das respostas. As entrevistas foram realizadas entre setembro de 2016 e julho de 2017. Ao todo, trinta e quatro pessoas envolvidas com os contratos de arrendamento de terras foram entrevistadas, das quais vinte são arrendatários (61\%) e quatorze arrendadores (39\%) de terras. Os dados provenientes das questões fechadas e abertas foram analisados, respectivamente, com auxílio do software Sphinx e por meio da análise de discurso.

O artigo está organizado em quatro seções além desta introdução. A primeira apresenta um breve histórico da região de estudo, a segunda busca explicar o fenômeno do arrendamento rural a partir das bases teóricas de Chayanov (1899/1974) e Shanin (1983). A terceira seção apresenta os principais resultados alcançados e a última sintetiza as principais conclusões, evidenciando que a prática de arrendamento de terras entre agricultores familiares representa, de um lado, um mecanismo para ampliar as atividades agropecuárias de agricultores familiares que lograram modernizar suas unidades produtivas e, de outro lado, uma forma seja de transição para o processo de aposentadoria, seja de alternativa de complementação de renda para aqueles que já se encontram aposentados.

\section{CONTEXTO EMPÍRICO: A REGIÃO MEIO OESTE DE SANTA CATARINA}

A história da região meio oeste do estado de Santa Catarina tem a Guerra do Contestado como evento incontornável. Entre os anos de 1912 e 1916, disputas por terras entre os estados do Paraná e Santa Catarina e entre agricultores de estatutos sociais diferentes resultaram num dos maiores conflitos sociais da história do Brasil (MASCARENHAS, 2015). De um lado, estavam posseiros, em sua maioria de origem cabocla, e, de outro, o Exército Brasileiro aliado a milícias privadas, contratadas pela empresa responsável pela construção da ferrovia que ligaria São Paulo ao Rio Grande do Sul, mas também grandes proprietários de terras (AURAS, 1995). De acordo com essa autora, com o fim dessa disputa e a derrota da população cabocla, a terra foi transformada em um bem de produção na região, o que acarretou a institucionalização da propriedade

\footnotetext{
${ }^{2}$ A categoria dos proprietários de terras absenteístas já era assim denominada por Marx (1979) em sua análise sobre a Comuna de Paris. Esse tipo de proprietário de terras apresenta como principal característica o fato de não administrar pessoalmente o seu negócio agropecuário, ou seja, não explora diretamente suas terras para fins produtivos.
} 
privada em detrimento da simples ocupação ou posse de terra, regime que ainda vigorava no início do século passado.

Um elemento central dessa disputa pela posse da terra foi a intensificação por parte do governo do processo de colonização da região Oeste Catarinense por famílias de descendência europeia (NODARI, 2009). Esse artifício estimulou a "expulsão" das terras de famílias que não possuíam documentos que lhes garantissem os seus direitos de propriedade, a favor da política de colonização por agricultores migrantes (BAVARESCO, 2005). O processo de colonização das terras levou a um esgotamento das fronteiras agrícolas da região no final dos anos de 1970.

A partir de então, um intenso processo de modernização da agricultura, com destaque para a implementação do setor agroindustrial de carnes (suínos e frangos), difundiu-se na região com o apoio do Estado. As agroindústrias se aproveitaram do potencial representado pela força de trabalho proveniente da mão de obra familiar e implementaram um modelo, designado de "sistema de integração", o qual consiste em contrato normativo de parceria entre a agroindústria e o agricultor familiar. Esse sistema perdura até hoje, sendo complementado atualmente pela produção leiteira, além dos cultivos de soja e milho (TECCHIO, 2012).

Em meados dos anos 1980, ocorreram diversas ocupações de terras na região oeste e extremo oeste do estado, organizadas pelo Movimento dos Sem Terra (MST). Desse processo, foram criados cinquenta projetos de assentamento de reforma agrária, que beneficiaram 2.266 famílias em nove municípios da região (INCRA, 2011). Esses assentamentos representaram a última investida de expansão física de áreas agrícolas (BAVARESCO, 2005) e a evidência de que o acesso a terra continua sendo um problema estrutural para uma parcela de agricultores familiares, em especial para os de origem cabocla (TECCHIO, 2012).

A região comporta, também, duas Terras Indígenas (TI Xapecó e TI Toldo Imbu) localizadas nos municípios de Entre Rios, Ipuaçu e Abelardo Luz, abrangendo um universo de 1.394 famílias indígenas. A TI Xapecó, maior delas, é composta por dezesseis aldeias, distribuídas em uma área de 16.284 ha, onde vive uma população de 5.338 indígenas (FUNAl, 2011). Há, portanto, nessa região, um elevado dinamismo socioeconômico decorrente do processo de colonização e uma heterogeneidade de usos da terra e de situações socioeconômicas, com a presença de assentamentos de agricultores sem terra e povos indígenas (GODOI, 2014). Para esses dois últimos segmentos sociais, o arrendamento de terras e o trabalho sazonal precário representam uma marca em suas trajetórias de vida.

\section{AGRICULTURA FAMILIAR E AS IMPLICAÇÕES TEÓRICAS DOS CONTRATOS DE ARRENDAMENTO RURAL}

$\mathrm{Na}$ agricultura de base familiar, com presença marcante na região de estudo, tende a prevalecer uma racionalidade determinada pela fusão entre produção, consumo e reprodução social. Segundo Wanderley (1996, p. 2), a agricultura familiar deve ser entendida "como aquela em que a família, ao mesmo tempo em que é proprietária dos meios de produção, assume o trabalho no estabelecimento produtivo. [...] o caráter familiar não é um mero detalhe superficial e descritivo: o fato de uma estrutura produtiva associar família-produção-trabalho tem consequências fundamentais para a forma como ela age econômica e socialmente" (WANDERELEY, 1996, p. 4). O agricultor familiar, para Carvalho (2004, p. 148), constitui-se "num sujeito social cujo movimento histórico se caracteriza por modos de ser e de viver que lhe são próprios". 
Dessa forma, a reprodução social da unidade de produção baseia-se na possibilidade crescente de melhoria das condições de vida e de trabalho da família.

Neste sentido, os preceitos teóricos formulados por Alexander Chayanov (1899/1974) e Teodor Shanin (1972/1983) permitem compreender a capacidade de reprodução social e desenvolvimento da agricultura familiar. Ainda que os estudos desses autores sejam baseados na realidade empírica da Rússia no final do século XVIII e início do século XIX, constituída por sociedades camponesas ${ }^{3}$, muitas das suas formulações continuam pertinentes para pensar a realidade social atual da categoria de agricultores familiares.

A noção chayanoviana de diferenciação demográfica auxilia a compreender o recurso do arrendamento de terras por parte de agricultores familiares, não sem considerar que os avanços tecnológicos verificados ao longo dos dois séculos que nos separam de seu estudo pioneiro alteraram com profundidade o jogo dos fatores de produção analisados pelo autor. Para muitos agricultores familiares contemporâneos, certamente, a centralidade da alocação da força de trabalho, fator de produção mais abundante na época de Chayanov, perdeu poder explicativo para o fator capital, pois muitas unidades familiares lograram elevados níveis de modernização por meio de investimentos em tecnologias de ponta graças a políticas públicas de crédito rural subsidiado.

\subsection{Ciclo de vida ou diferenciação demográfica}

A obra de Chayanov (1974) contribuiu para a construção de uma teoria sobre o comportamento do agricultor familiar alicerçada no ciclo de vida familiar. O pressuposto de base desse autor consiste em afirmar que a economia de base familiar representa um sistema econômico com lógica própria, com especificidades e motivações diferentes da agricultura de base eminentemente capitalista. Na diferenciação demográfica, o elemento central é o tamanho da família, o que está diretamente relacionado com o seu ciclo de desenvolvimento. Seu principal argumento é que as variações na força de trabalho disponível determinam a ocupação mais ou menos intensiva da terra. A composição familiar define antes de tudo os limites máximo e mínimo do volume de sua atividade econômica.

Cada família, segundo sua idade, constitui em suas diferentes fases um aparato de trabalho completamente distinto de acordo com a sua força de trabalho, a intensidade da demanda das suas necessidades, a relação consumidor/trabalhador e a possibilidade de aplicar os princípios da cooperação. (CHAYANOV, 1974, p. 56).

Deste modo, a família opera tanto como unidade de produção quanto de consumo, tendo como objetivo suprir as necessidades básicas de seus membros. Na Unidade de Produção Camponesa (UPC), a intensificação da utilização do trabalho pode acontecer "simplesmente pela pressão das forças internas da unidade, quase sempre devido ao tamanho da família ser desfavoravelmente proporcional à extensão da terra cultivada" (CHAYANOV, 1974, p. 141).

O autor relaciona, então, a produção da unidade camponesa à abordagem da "história natural" da família, que se inicia a partir do matrimônio do casal e se estende até a chegada dos

\footnotetext{
${ }^{3}$ Wanderley (2000, p. 2) questiona a concepção de muitos autores contemporâneos, que consideram que a categoria sociológica do campesinato tenha perdido sentido na atualidade, dada sua decomposição ou "subordinação às novas formas de capital no campo". Para ela, "se estamos, hoje, discutindo o significado da agricultura familiar neste novo contexto da integração da agricultura e do meio rural é porque esta outra forma social de produção ocupa um lugar importante no cenário atual da economia e da sociedade brasileira".
} 
filhos e a idade produtiva destes, sendo que o ciclo se reinicia com o casamento da segunda geração. O tamanho da área cultivada depende do tamanho da família e do ciclo do seu desenvolvimento. Quanto mais nova é a família e com maior número de filhos em idade não ativa, menor será o tamanho da área cultivada, pois as pessoas em idade produtiva serão em menor número. Já em famílias com maior número de pessoas e em idade produtiva, maior pode ser a área cultivada, pois a relação entre produtores e consumidores será maior.

Para Chayanov (1974, p. 105), "o aumento do volume da atividade avança sempre em proporção ao crescimento da família e diminui com a mesma rapidez do desenvolvimento da intensificação de capital". Ou seja, a composição da família é considerada um fator determinante nos processos de decisões das unidades de produção, principalmente no que diz respeito aos investimentos e ao grau de autoexploração.

Neste sentido, a teoria do ciclo de vida familiar auxilia a compreender, na atualidade, o recurso ao arrendamento de terras. Quando a razão trabalhadores/consumidores aumenta e atinge o auge da capacidade produtiva (os integrantes em idade ativa na unidade de produção familiar estão em maior número que as crianças e os idosos), o arrendamento de terras de terceiros pode ser utilizado como uma estratégia para elevar a produção e os rendimentos. Por sua vez, quando essa razão começa a decair, decresce também a capacidade produtiva no interior da unidade agrícola familiar. Diante da redução do fator de produção trabalho e a proximidade da aposentadoria rural, o arrendamento de terras próprias para terceiros pode ser utilizado para reduzir de forma gradativa os negócios agrícolas. A Figura 1, a seguir, ilustra esse processo em uma unidade agrícola familiar. De forma complementar, demonstra-se que, na "primeira geração", a presença de sucessores familiares explica a inexistência de terras próprias arrendadas para terceiros. Já na "segunda geração", a falta de membros da família para dar continuidade às atividades agropecuárias justifica a tendência a ofertar terras para o arrendamento de terceiros.

Figura 1 - Ciclo de vida familiar com base em Chayanov

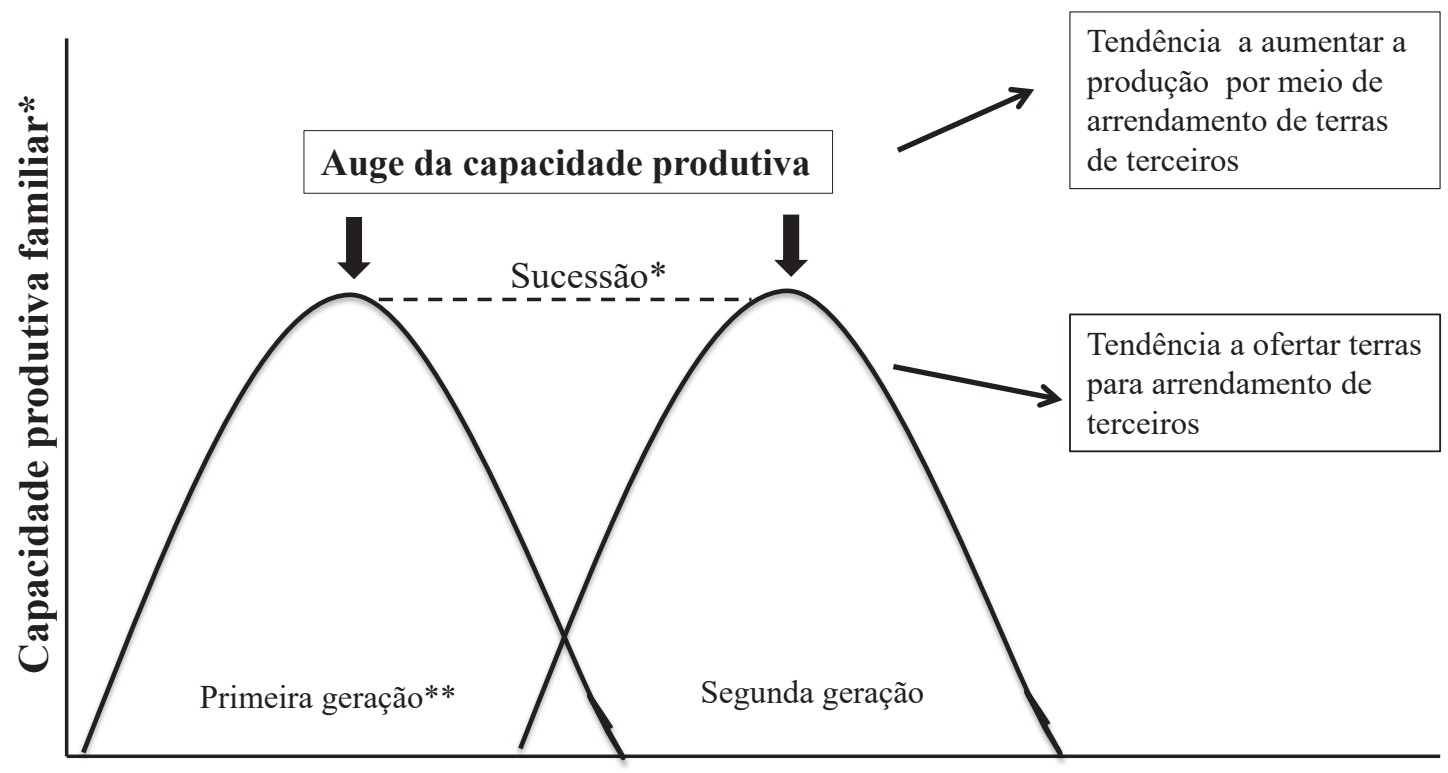

Tempo (anos)

*Representa a razão trabalhadores/consumidores

** Quando houver um processo de sucessão, o auge da capacidade produtiva estende-se por mais tempo. Fonte: Os autores (2016). 
Segundo Woortmann (2001, p. 5), durante certo período de tempo, a razão consumidores/ produtores aumenta para, depois, começar a diminuir e "quanto maior a razão consumidores/ produtores, tanto mais alta será a intensidade do trabalho dos produtores (que também são consumidores)". Nesse ponto, uma das alternativas a serem adotadas pela família pode ser dispor parte das terras próprias para outras unidades agrícolas familiares que se encontram numa situação inversa.

Conforme mencionado acima, a abordagem chayanoviana precisa ser relativizada, pois no seu tempo a importância da tecnologia como fator de produção era profundamente inferior à existente hoje. Ou seja, as famílias contemporâneas de agricultores com poucos filhos ou que ainda não estejam em idade de trabalho podem compensar a falta de força de trabalho familiar com o uso da mecanização automotriz e contratação, temporária ou permanente, de mão de obra. No entanto, a formulação de Chayanov mantém sua força explicativa nas situações muito recorrentes na atualidade de êxodo definitivo dos filhos, o que resulta na inexistência de sucessor para dar continuidade ao negócio agrícola familiar.

Ainda, na busca por maiores ganhos financeiros, determinadas famílias ou membros da unidade familiar, além de utilizar a terra e os meios de produção que dispõem, buscam outras formas de trabalho que proporcionem condições mais vantajosas. Embora o autor não utilize a noção de pluriatividade, empregada na atualidade para analisar as demais fontes de renda presentes nas unidades agrícolas familiares, sua análise sugere que o trabalho externo dos componentes da família pode alterar de forma significativa a intensidade de uso do fator terra. Schneider (2003, p. 106) ressalta que a obra de Chayanov faz menção a outras "atividades não agrícolas" desenvolvidas fora das unidades de produção, exercidas por membros das famílias. Trata-se, portanto, de uma estratégia complementar para obtenção de renda e de inserção econômica, também associada ao estágio de diferenciação demográfica, que tem implicações sobre a utilização das terras.-

Além disso, a abordagem de Chayanov (1974) avança no sentido de demonstrar que esse recurso não concerne somente às famílias com pouca terra. A existência de um mercado de trabalho externo pode afetar a estratégia familiar de investir trabalho e capital na produção agropecuária independentemente do tamanho da unidade produtiva. Segundo o autor, quando há mão de obra disponível na unidade de produção que não esteja sendo utilizada, esta tende a se voltar a atividades artesanais e a outras atividades não agrícolas para alcançar o equilíbrio econômico com as necessidades da família.

No que concerne à compra ou ao arrendamento de terras, a partir da abordagem de Chayanov, pode-se concluir que a decisão dependerá de como os recursos produtivos da família estão sendo empregados e se a satisfação das necessidades estiver sendo atingida. Caso o fator de produção/trabalho não esteja sendo utilizado no seu nível de equilíbrio, existem estímulos para ou alocá-lo em atividades externas ou aumentar a área cultivada através da compra ou do arrendamento de terras de terceiros.

\subsection{A teoria das mobilidades substanciais}

A teoria de Shanin (1983) articula-se com a formulação de Chayanov a partir do ciclo de vida familiar. Para esse autor, as determinantes demográficas respondem pelas diferenças econômicas e mobilidades das unidades agrícolas familiares. O autor explica o significado de mobilidade por 
meio do funcionamento da família como unidade de produção de recursos fortemente sujeita às forças da natureza, mercado e estímulos (positivos e negativos) do Estado. Esses determinantes externos seriam responsáveis por uma parte significativa da mobilidade das famílias.

O ciclo biológico da família - nascimento, crescimento até alcançar a fase adulta, matrimônio, desenvolvimento dos filhos, envelhecimento e morte - conduz a mudanças regulares de caráter cíclico. De acordo com Shanin (1983), o aumento da família origina um consumo adicional, e com o crescimento dos filhos tem-se um aumento na força de trabalho, mas também do consumo da família, o que, em alguns casos, gera problemas de emprego da mão de obra. Assim, o crescimento biológico da família pode resultar na elevação do quociente consumidor/ trabalhador e da pressão consumidora. Para expandir os rendimentos da família, pode-se lançar mão da compra ou do arrendamento de terras. A morte ou a retirada do chefe da família, na maioria das vezes, representa o começo de um novo ciclo para os jovens (SHANIN, 1983, p. 59).

Portanto as unidades agrícolas dependem de movimentos próprios do ciclo de vida das famílias. Nas fases demográficas crescentes, os agricultores familiares tendem a expandir o seu patrimônio e, nos períodos declinantes, a desfazerem-se dele. Isso conduz a um incremento na intensidade do trabalho, na autoexploração dos seus membros e na busca de fatores de produção adicionais, como é o caso do arrendamento de terras. Então, pode-se afirmar que a mobilidade em nenhum momento se caracteriza como linear, com direção única, mas como um processo dinâmico, que não tem causa e direção unilateral, tratando-se de uma mobilidade multidirecional (SHANIN, 1983).

Às transmutações das unidades camponesas [que] resultam no seu aparecimento e desaparecimento dentro das comunidades rurais deu-se o nome de "mobilidades substanciais". Este termo inclui processos de repartição, fusão, extinção e migração de famílias. [...] A repartição produz resultados no aparecimento de novas unidades. Extinção e fusão conduzem ao desaparecimento. Com a emigração, uma família camponesa desaparece, para reaparecer em outra comunidade (tais como a imigração). O termo "alterações substanciais" abrange, portanto, amplamente diferentes tipos de processos sociais, mas com uma característica em comum: o seu impacto diferencial que se reflete na forma de tendências de nivelamento das sociedades camponesas. (SHANIN, 1983, p. 172).

Para Shanin (1983), a repartição era mais intensa em famílias mais capitalizadas e com unidades produtivas com maior extensão, enquanto o desaparecimento por fusão, extinção e emigração estava inversamente correlacionado com o tamanho e condição financeira. Um número considerável de unidades mais pobres se extingue paulatinamente. Por conseguinte, tanto a repartição como o desaparecimento geram tendências niveladoras, operando em direção oposta à polarização econômica. Na atualidade, as oscilações aleatórias naturais, políticas ou de mercado têm agravado os efeitos dos movimentos em qualquer que seja a sua direção, de modo que certas unidades produtivas podem falir e vir a desaparecer, enquanto outras podem ter os seus operadores extraordinariamente bem-sucedidos.

\section{A PRÁtICA DO ARRENDAMENTO DE TERRAS NA REGIÃO MEIO OESTE DE SANTA CATARINA}

As teorias do ciclo de vida familiar e das mobilidades substanciais relacionam-se com o processo que vem ocorrendo na região de estudo no que se refere ao arrendamento de terras. Observou-se nas famílias estudadas que, quando essas estão em idade ativa e com mão de obra 
disponível na unidade de produção agrícola, aumenta a demanda por terras de terceiros. Essa demanda se expressa tanto pelo interesse de certos agricultores em comprar quanto em arrendar terras. O processo inverso também foi verificado, pois, com o avançar da idade e diante da falta de sucessores, os responsáveis pela gestão da unidade agrícola familiar tendem a não investir no aumento de área da unidade produtiva, nem em máquinas e implementos agropecuários. O arrendamento de terras para terceiros apresenta-se com um recurso para manter a unidade produtiva, sem dela precisar desfazer-se. A seguir, a partir de dados coletados a campo, será apresentada detalhadamente a relação entre as teorias de ciclo de vida e mobilidades substanciais com o tema do arrendamento de terras.

\subsection{Implicações dos contratos de arrendamento e a relação com ciclo de vida familiar}

Com o propósito de melhor compreender o arrendamento de terras a partir da noção de diferenciação demográfica das famílias, estabeleceu-se uma relação entre a idade dos agricultores engajados nos contratos de arrendamento e a opção de arrendar terras (tanto tomar terras de terceiros quanto ceder suas terras para terceiros). Os agricultores e proprietários de terras absenteístas foram classificados em quatro categorias segundo a idade: até 34 anos, jovens agricultores no início da vida ativa; de 35 a 49 anos, agricultores no auge da vida ativa; de 50 a 60 anos, agricultores ainda na vida ativa, porém, em fase de transição para a aposentadoria; e mais de 60 anos, agricultores aposentados ou em vias de se aposentar ${ }^{4}$. Para essa análise, tomaram-se como referência os "chefes de estabelecimentos", que nesta pesquisa são $94 \%$ do sexo masculino.

Na categoria de até 34 anos, quatro casos tomam terras de terceiros para arrendamento e dois casos disponibilizam terras para arrendamento. Essas duas situações correspondem a proprietários de terras absenteístas, que não as exploram diretamente para fins financeiros. No caso dos quatro agricultores arrendatários, neste momento do ciclo de vida, a unidade de consumo é maior que a unidade de produção, mas, por estarem no auge da juventude e por terem modernizado o parque de máquinas, a maioria desses agricultores encontra estímulos para aumentar a sua produção por meio do arrendamento. Essa modernização se explica pela criação em meados dos anos 1990 de uma política pública de crédito rural subvencionado específica para a agricultura familiar. Mais recentemente, essa política incentivou de forma contundente a renovação de máquinas e implementos agropecuários de unidades agrícolas familiares.

Na categoria entre 35 e 49 anos, enquadram-se dezessete entrevistados, que se encontram no auge da sua força produtiva. Desses, doze são arrendatários e cinco arrendadores. Nessa fase do ciclo de vida, a unidade de trabalho é maior que a unidade de consumo, o que indica a disponibilidade de mão de obra para aumentar a produção. Esses agricultores vislumbram no arrendamento uma maneira de expandir os rendimentos da família e utilizar a mão de obra e maquinários disponíveis na unidade de produção. Dos cinco casos restantes, três são representados por proprietários de terras absenteístas, que não residem na unidade de produção e optam por ceder a totalidade das suas terras a terceiros. Os dois outros casos são agricultores

\footnotetext{
${ }^{4}$ Reestruturado pela Constituição de 1988, o sistema público de aposentadoria rural beneficia, atualmente, cerca de 5,3 milhões de famílias rurais, com quase nove milhões de benefícios. Para receber um salário mínimo, os agricultores precisam comprovar tempo de serviço de até 15 anos no meio rural e ter idade acima de 55 anos no caso das mulheres e 60 anos no dos homens (CAZELLA et al., 2016).
} 
que, pela precariedade da infraestrutura existente na unidade produtiva, cedem uma parte das suas terras para terceiros.

Ressalte-se que as duas primeiras categorias de agricultores (até 34 anos e de 35 a 49 anos de idade) apresentam como característica principal o fato de seus integrantes encontrarem-se no auge das suas forças físicas e técnicas, potencializadas nas últimas décadas pelo acesso à política de financiamento rural. No caso dos que tomam terras arrendadas, suas unidades produtivas apresentam um parque de máquinas com capacidade para cultivar terras de terceiros. Além disso, os agricultores arrendatários dessas categorias, em sua maioria, conjeturam no arrendamento a possibilidade de acessar novas áreas para cultivos mais rentáveis. Esses agricultores afirmam que procuram terras próximas ${ }^{5}$ às suas e de pessoas conhecidas, pois isso representa uma garantia maior no cumprimento dos contratos.

Segundo Neumann (2003), a proximidade física das glebas a serem arrendadas representa redução de custos adicionais com deslocamentos de pessoas e maquinários (circulação/transporte da família, animais e máquinas, cercas e vigilância). Adicionalmente, essa proximidade viabiliza o trabalho conjunto da mão de obra familiar e mantém uniforme a porção territorial que a família cultiva (CASTRO, 2017). Além disso, as similaridades das características naturais da área arrendada, a exemplo de solo, vegetação, recursos hídricos e declividade do terreno, contribuem para a procura de terras nas proximidades do próprio estabelecimento.

Entre os sete agricultores que se encontram na faixa etária de 50 a 60 anos, quatro casos aumentam seus rendimentos por meio do arrendamento de terras, sendo o principal estímulo dessa categoria a presença de sucessores para dar continuidade aos negócios da unidade produtiva. Os arrendadores representam os outros três casos, os quais optam por dispor as suas terras para terceiros por estarem enfrentando dificuldades de acesso a políticas públicas ou pela falta de mão de obra familiar. Ou seja, esses agricultores não têm herdeiros interessados em dar prosseguimento às unidades agrícolas familiares. Um deles é proprietário de uma unidade produtiva altamente tecnificada, mas a falta de sucessor para assumir a atividade agrícola explica o arrendamento das terras para um irmão mais novo, proprietário de outra unidade agrícola com elevados índices técnicos. Segundo Carneiro (1998), os destinos das unidades produtivas sem perspectivas sucessórias são os mais variados, podendo tanto ser arrendadas para parentes ou vizinhos que permanecem na atividade agrícola quanto ficarem abandonadas ou mesmo serem vendidas. Ressalta-se, porém, que a opção de venda é pouco recorrente na região de estudo, principalmente entre os agricultores mais velhos, os quais ainda demostram apego à unidade produtiva.

Por fim, dentre os quatro agricultores em idade superior a 60 anos e, portanto, já aposentados, todos afirmam ceder suas terras para terceiros por não terem sucessores da unidade produtiva. Neste momento, a unidade de consumo é maior que a unidade de produção e, devido à idade avançada e à inexistência de sucessor, esses agricultores não têm mais estímulos para continuar investindo e produzindo na unidade agrícola familiar. Nestes casos, percebe-se uma clara opção por manter por um tempo maior o patrimônio familiar em vez de recorrer de

\footnotetext{
${ }^{5}$ Neumann (2003, p. 27) contatou que, quando um dos cônjuges recebe terras de herança da partilha de bens dos pais, pode haver uma fragmentação das propriedades em parcelas não contíguas, o que representa um "processo de dispersão geográfica das terras das propriedades, e é resultado da pressão demográfica que força os agricultores a buscarem novas áreas". Por vezes, terras herdadas localizadas distantes da unidade produtiva principal podem ser ofertadas para arrendamento de terceiros.
} 
imediato à venda das suas terras. O recurso do arrendamento de terras para terceiros, além de propiciar a manutenção de certo nível de rendimento financeiro, retarda a difícil decisão de vender o patrimônio familiar, quase sempre marcado por valores simbólicos construídos, por vezes, por mais de uma geração familiar (MATTE et al., 2014).

Observou-se a campo que o ato de se tornar arrendador representa não só uma oportunidade de manter o patrimônio familiar, mas também de preservar o estatuto social de agricultor. Nesses casos, não deixam de residir no estabelecimento e continuam sendo "caracterizados" pelos seus pares e representantes de organizações profissionais agrícolas como agricultores (CASTRO, 2017). A alternativa do arrendamento representa, também, uma forma de manter o patrimônio familiar e evitar o seu desaparecimento para proprietários de terras que as herdaram de gerações anteriores, mas desenvolvem outras atividades econômicas fora do setor agrícola (ALMEIDA; BUAINAIN, 2013). Além disso, os contratos de arrendamento podem representar uma fase intermediária que antecede a venda da propriedade por agricultores aposentados ou próximos da aposentaria que, em definitivo, não têm sucessores interessados em retomar a atividade agropecuária.

\subsection{0 arrendamento rural no processo sucessório}

As abordagens de Chayanov (1899/1974) e Shanin (1983) apresentadas acima apontam a diferenciação demográfica das famílias e a presença de filhos em idade ativa para auxiliar nas atividades agropecuárias como fatores determinantes para os agricultores familiares recorrerem ao arrendamento de terras como forma de expandir os rendimentos. Com o propósito de correlacionar os dados de campo com os pressupostos teóricos desses autores, estabeleceu-se uma correlação entre a opção de arrendar (tanto tomar terras quanto ceder) e a presença de, pelo menos, um filho em idade ativa no estabelecimento agropecuário.

Entre os vinte agricultores arrendatários que aumentam seus cultivos por meio do arrendamento rural, onze apresentam sucessores dispostos a dar continuidade aos trabalhos na unidade produtiva, sendo oito casos na categoria de faixa etária de 35 e 49 anos e três casos na de 50 a 60 anos. Ou seja, a maioria encontra-se no auge das suas forças produtivas e dispõe de sucessores. Além disso, o arrendamento de terras, aliado à presença de sucessores, apresenta uma forte ligação com o acesso a políticas públicas. Esses agricultores, ao modernizarem suas atividades por meio do acesso ao crédito rural e a consequente aquisição de máquinas e implementos agropecuários, vislumbram no arrendamento de terras uma forma de potencializar os retornos econômicos desses investimentos. A existência de um parque de máquinas superdimensionado se justifica pelo recurso ao arrendamento de terras de terceiros, expandindo, assim, a sua produção e estimulando os filhos a permanecerem nas unidades produtivas.

Os outros nove casos não possuem filhos em idade ativa ou dada a baixa idade ainda não podem ser considerados sucessores da unidade agrícola familiar. Por representarem, ao mesmo tempo, sucessores potenciais e membros da família que aumentam a unidade de consumo em relação ao potencial de trabalho, o arrendamento de terras pode representar tanto uma estratégia de reprodução social imediata quanto de ampliação dos rendimentos, visando à estruturação ao longo do tempo de uma unidade produtiva viável do ponto de vista econômico. Essa situação representa maiores chances de algum filho dar continuidade à unidade agrícola familiar.

Já entre os quatorze arrendadores, onze casos não possuem filhos em idade ativa no estabelecimento, o que está diretamente relacionado com a intenção de dispor suas terras para 
terceiros. Destes, cinco casos são caracterizados por proprietários de terras absenteístas que arrendam a totalidade das terras. Os outros seis casos são em sua maioria agricultores em idade avançada, que cedem a totalidade ou parte das suas terras para terceiros, e, destes, um chefe de estabelecimento é pluriativo, ou seja, realiza atividade fora do estabelecimento como fonte complementar de renda.

Entre os outros três casos que, mesmo tendo filhos para auxiliar no trabalho agropecuário, optam por dispor suas terras para arrendamento de terceiros, a precariedade de infraestrutura na unidade produtiva explica em grande parte a opção por ceder terras para arrendamento. Ou seja, esses agricultores são menos capitalizados e encontram dificuldades principalmente em acessar crédito rural. Além disso, dois possíveis sucessores realizam trabalhos remunerados fora das unidades produtivas, dividindo seu tempo entre o trabalho na cidade e no campo. De acordo com Carneiro (1998), os processos econômicos recentes transformam o rural em um espaço cada vez mais heterogêneo, diversificado e não exclusivamente agrícola. O arrendamento de terras para terceiros representa aqui uma estratégia de reprodução social que se articula com outras fontes de renda decorrentes da pluriatividade de membros da família.

\section{CONSIDERAÇÕES FINAIS}

O presente artigo analisou os principais elementos condicionantes dos arrendamentos de terras agrícolas no meio rural, sobretudo, entre diferentes categorias e ciclos de vida de agricultores familiares. Para tanto, foram considerados os discursos e as narrativas de trinta e quatro atores sociais, sendo vinte nove agricultores e cinco proprietários de terras. Desse total de entrevistados, vinte são arrendatários e quatorze arrendadores de terras. As entrevistas revelaram elementos econômicos e sociais que condicionam os contratos agrários de arrendamento rural.

Nos relatos dos entrevistados, percebe-se que o arrendamento rural representa uma estratégia de manutenção do patrimônio familiar por parte de famílias em idade avançada e um incentivo entre as famílias mais novas para a sua permanência no meio rural. Assim, essa estratégia possibilita tanto a reprodução social de agricultores familiares consolidados quanto de agricultores menos capitalizados ou em idade avançada sem sucessores para dar continuidade ao negócio familiar.

O arrendamento de terras por agricultores familiares está associado, portanto, a situações socioeconômicas de outros agricultores que, por razões diversas, estão cessando ou já encerraram as suas atividades agrícolas, mas que desejam preservar o patrimônio familiar, alugando as terras para agricultores que continuam ativos e almejam ampliar as suas atividades agropecuárias. Trata-se de um importante mecanismo de gestão da malha fundiária ainda pouco conhecido no Brasil, mas que representa a principal forma de acesso a terra em diversos países.

A partir das entrevistas realizadas no quadro deste estudo, pôde-se identificar que a prática do arrendamento induz a uma combinação de fatores políticos, sociais e econômicos, que merecem novas e mais profundas pesquisas. O arrendamento pode se tornar um mecanismo de política pública que incentive jovens agricultores a permanecer no meio rural e a investir em atividades agropecuárias. Em países onde esse tipo de política já existe, o arrendamento de terras representa a principal forma de jovens agricultores não imobilizarem recursos financeiros significativos em terras, alocando esses recursos em investimentos de caráter produtivo. Ademais, o reconhecimento e fortalecimento do arrendamento rural estão associados a mecanismos de acesso ao crédito rural, que asseguram a estabilidade dos processos de investimento, realizando 
um adequado gerenciamento dos recursos naturais e propiciando maior lucratividade das unidades produtivas.

\section{REFERÊNCIAS}

AURAS, M. Guerra do contestado: a organização da irmandade cabocla. Florianópolis: Cortez, 1995.

ALMEIDA, P. J; BUAINAIN, M. A. Os contratos de arrendamento e parceria no Brasil. Revista Direito GV, v. 9, n. 1, São Paulo, p. 319-43, jan./jun. 2013.

BAVARESCO, P. R. Ciclos econômicos regionais: modernização e empobrecimento no Extremo Oeste catarinense. 1. ed. Chapecó: Argos, 2005.

BRASIL. Ministério da Reforma e do Desenvolvimento Agrário. Lei n. 4.504, de 30 de novembro de 1964. Dispõe sobre o Estatuto da Terra e dá outras providências. Brasília: MIRAD, 1985.

CASTRO, L. F. P. Dimensões e lógicas do arrendamento rural na agricultura familiar: um estudo de caso. Revista em Agronegócio e Meio Ambiente, Maringá, v. 10, n. 2, p. 437-57, abr./jun. 2017.

CARNEIRO, M. J. O Ideal Rurbano: campo e cidade no imaginário de jovens rurais. In: SILVA, F. C. T.; SANTOS, R.; Costa, L. F. C. (Org.). Mundo rural e política: ensaios interdisciplinares. Rio de Janeiro: Campus, 1998.

CARVALHO, H. M. O campesinato no século XXI: possibilidades e condicionantes do desenvolvimento do campesinato no Brasil. 1. ed. Petrópolis: Vozes, 2004.

CAZella, A. A.; CAPellesso, A. J.; MedeIROS, M.; TeCCHIO, A.; SENCÉBÉ, Y.; BúRIGOL, F. L. Políticas públicas de desenvolvimento rural no Brasil: o dilema entre inclusão produtiva e assistência social. Revista Política e Sociologia, Florianópolis, v. 15, n. 37, p. 49-79. set. 2016. Disponível em: https://periodicos.ufsc. br/index.php/politica/article/view/2175-7984.2016v15nesp1p49. Acesso em: 12 mar. 2017.

CHAYANOV, A. V. La organización de la unidad económica campesina. 2. ed. Buenos Aires: Nueva Visión, 1974.

FUNDAÇÃO NACIONAL DO ÍNDIO (FUNAI). Terra Indígena Xapecó. Terras indígenas no Brasil. 2011. Disponível em: https://terrasindigenas.org.br/es/terras-indigenas/3906. Acesso em: 11 jan. 2017.

GODOI, T. G. Dilemas e perspectivas da sustentabilidade nas políticas de crédito para a agricultura familiar: estudo de caso no território do Meio Oeste Contestado (SC). 2014. 126p. Dissertação (Mestrado em Agroecossistemas) - Universidade Federal de Santa Catarina, Florianópolis, SC, 2014.

INSTITUTO NACIONAL DE COLONIZAÇÃO E REFORMA AGRÁRIA. Perfil da Agricultura Familiar no Brasil: dossiê estatístico. Brasília: INCRA, 2011.

MARX, K. Carta a K. Schmidt. In: MARX, K.; ENGELS, F. A comuna de Paris. Belo Horizonte: Aldeia Global, 1979.

MASCARENHAS, G. A. Consórcios públicos e arranjos institucionais de desenvolvimento territorial no meio oeste contestado: cooperação ou competição? 2015. 148p. Dissertação (Mestrado em Ciências Humanas e Sociais) - Universidade Federal do Rio de Janeiro, Rio de Janeiro, RJ, 2015.

MATTE, A.; CHECHI, L.; BOSCARDIN, M.; SPANEVELLO, R. M.; ANDREATTA, T. Fatores condicionantes a permanência ou saída dos filhos em propriedades de agricultura e pecuária familiar no Rio Grande do SUl. In: CONGRESSO DA SOCIEDADE BRASILEIRA DE ECONOMIA, ADMINISTRAÇÃO E SOCIOLOGIA RURAL, 52., 2014, Goiânia. Anais [...]. Goiânia: Sober, 2014. p. 1-14. 
NEUMANN, P. S. O impacto da fragmentação e do formato das terras nos sistemas familiares de produção. Orientador: Carlos Loch. 2003. 326f. Tese (Doutorado em Engenharia de Produção)- Universidade Federal de Santa Catarina, Florianópolis, SC, 2003.

NODARI, E. S. Etnicidades renegociadas: práticas socioculturais no oeste de Santa Catarina. Florianópolis: Editora da UFSC, 2009.

SHANIN, T. La clase incómoda: sociología política del campesinado en una sociedad en desarrollo (Rússia 1910-1925). Versión Española de Fernando Andrada Tápia. 3. ed. Madri: Alianza, 1983.

SCHNEIDER, S. A Pluriatividade na agricultura familiar. Porto Alegre: Ed. Porto Alegre: UFRGS, 2003.

TECCHIO, A. Políticas públicas de desenvolvimento territorial e superação da pobreza no meio rural brasileiro: estudo de caso no território Meio Oeste Contestado (SC). Orientador: Ademir Antonio Cazzela 2012. 183f. Dissertação (Mestrado em Agroecossistemas) - Universidade Federal de Santa Catarina, Florianópolis, SC, 2012.

WANDERLEY, M. N. Raízes históricas do campesinato brasileiro. In: TEDESCO, João Carlos (Org.). Agricultura familiar: realidades e perspectivas. Passo Fundo: Universidade de Passo Fundo, 2000.

WOORTMANN, K. O modo de produção doméstico em duas perspectivas: Chayanov e Sahlins. Revista Habitus, Brasília, v. 2, n. 293, p. 93-131, mar. 2001.

\section{Sobre os autores:}

Ana Cecília Guedes: Doutoranda em Agroecossistemas pela Universidade Federal de Santa Catarina (UFSC). Mestre em Extensão Rural pela Universidade Federal de Santa Maria (UFSM). Engenheira Agrônoma pela UFSM. Tecnóloga em Processos Gerenciais pela Faculdade de Tecnologia Internacional. E-mail: aninhaguedes86@hotmail.com, Orcid: http://orcid.org/0000-0001-8814-4858

Ademir Antonio Cazella: Doutor em Ordenamento Territorial pelo Centre d'Etudes Supérieures d’Aménagement, Tours, França. Mestre em Desenvolvimento, Agricultura e Sociedade pela Universidade Federal Rural do Rio de Janeiro (UFRRJ) e Engenheiro Agrônomo pela Universidade Federal de Santa Catarina (UFSC). Professor titular do Programa de Pós-Graduação em Agroecossistemas da UFSC. E-mail: aacazella@gmail.com, Orcid: http://orcid.org/0000-0002-4457-4853 
